\title{
Bioatividade de extratos de própolis sobre o pulgão Myzus persicae Sulzer (Hemiptera: Aphididae) em couve manteiga
}

Bioactivity of propolis extracts on the Myzus persicae Sulzer (Hemiptera: Aphididae) aphid in kale

\section{Aline Marielle de Souza Rocha, Alana Juliete da Silva Santos e Rita de Cássia Rodrigues Gonçalves- Gervásio*}

Recebido em 18/12/2016 / Aceito em 23/03/2017

\section{RESUMO}

Considerando a relevância do pulgão-verde (Myzus persicae) como praga para diversas hortaliças, o objetivo deste trabalho foi avaliar o efeito de extrato de própolis sobre o comportamento e mortalidade desse afídeo. Além disso, caracterizouse quimicamente a própolis utilizada, a qual foi coletada em colmeias de Apis melifera no Campus Ciências Agrárias da Universidade Federal do Vale do São Francisco (CCA/UNIVASF) em Petrolina, PE. Para a preparação do extrato, foram utilizados $30 \mathrm{~g}$ de própolis bruta triturada para cada $100 \mathrm{~mL}$ de solução alcoólica hidratada (70\%), por um período de 10 dias, obtendo-se a solução estoque. A partir desta, foram feitas diluições para as concentrações de 10 , 20,30 e $40 \%$ em água destilada. Foram realizados bioensaios de atratividade (com e sem chance de escolha) e mortalidade, utilizando discos de folhas de couve manteiga tratados com extratos nas diferentes concentrações e testemunha. Diante dos resultados, foi possível verificar que o extrato alcoólico de própolis em baixas concentrações exerce atração sobre o pulgão-verde, enquanto em concentrações acima de $20 \%$, o mesmo extrato repele indivíduos dessa espécie. O extrato alcoólico de própolis apresenta efeito tóxico ao pulgão-verde, provocando níveis crescentes de mortalidade à medida que se aumenta a concentração do mesmo.

PALAVRAS-CHAVE: pulgão-verde, Brassica oleraceae, produtos naturais, MIP.

\section{ABSTRACT \\ Considering the importance of green peach aphid (Myzus persicae) a pest of various vegetables, the

objective of this study was to evaluate the effect of propolis extract on the behavior and mortality of the aphid and to study chemically characterized propolis. Propolis used in this study was collected in Apis mellifera honeybee hives at UNIVASF on the Agricultural Sciences Campus. For the preparation of the extract, $30 \mathrm{~g}$ of ground crude propolis per $100 \mathrm{~mL}$ of hydrous alcoholic solution (70\%) were used during a period of 10 days to yield the stock solution. The same extract was diluted to concentrations of 10, 20, 30 and $40 \%$ in distilled water, obtaining the extract ready for use in testing. Bioassays attractiveness (free and no-choice) and mortality were carried out using kale leaf discs immersed in the extract and in the control. Given the results, it was found that the alcoholic extract of propolis in low concentrations exerts pull on the green peach aphid. In over $20 \%$ concentrations, however, the same extract repels individuals of that species. The alcoholic extract of propolis is toxic to the green peach aphid, causing increasing levels of mortality as the concentration of the extract increases.

KEYWORDS: green peach aphid, Brassica oleraceae, natural products, IPM.

O pulgão-verde, Myzus persicae (Sulzer, 1776) (Hemiptera: Aphididae), é um afídeo de grande interesse econômico, por apresentar uma extensa gama de hospedeiros. A contínua sucção de seiva provoca o enfraquecimento das plantas e o encarquilhamento de suas folhas, depreciando o produto. Essa espécie também está associada a danos indiretos como o desenvolvimento de fumagina e injeção de toxinas durante o processo de alimentação, além de atuar como eficiente vetor de vírus em mais de 100 espécies de plantas (RAJABASKAR et al. 2013). 
O controle de pulgões em sistemas convencionais de produção de hortaliças se baseia, principalmente, no uso de inseticidas sintéticos. $\mathrm{O}$ uso indiscriminado desses produtos, entretanto, pode ocasionar efeito negativo sobre predadores, parasitoides e entomopatógenos, o que contribui para a ressurgência da praga alvo, ou para elevação da população de outros artrópodes fitófagos (VAN DE VRIE et al. 1972). Outro problema cada vez mais frequente é o surgimento de populações resistentes, como consequência da pressão de seleção decorrente do uso intensivo de inseticidas com o mesmo mecanismo de ação (MILLER et al. 2010).

A procura por alimentos produzidos com maior responsabilidade social, econômica e ambiental, vem trazendo uma mudança na preferência do consumidor por produtos de boa qualidade e livres de resíduos de agrotóxicos. Dessa forma, para atender a essa demanda, as pesquisas estão voltadas para a redução de aplicação de produtos fitossanitários e à descoberta de substâncias naturais eficazes no controle de pragas (MACHADO et al. 2007). Nesse sentido, a própolis tem mostrado resultados interessantes quanto ao seu efeito tóxico sobre algumas espécies de artrópodes (OLIVEIRA et al. 2004, SILVA et al. 2004).

A própolis é uma resina de mistura complexa, coloração e consistência variada coletada por abelhas como as da espécie Apis mellifera Linnaeus, 1758. Ela é constituída por material resinoso e balsâmico oriundo de diversas partes das plantas, como gemas vegetativas, botões florais e exsudados resinosos, juntamente com secreções salivares e enzimas (PEREIRA et al. 2002). Suas propriedades biológicas estão diretamente ligadas a sua composição química, e dependem da flora de cada região visitada pelas abelhas e da época de colheita (CASTRO et al. 2007, VIÉGAS 2011).

Considerando que a apicultura é uma atividade que tem crescido entre agricultores de base familiar no Semiárido Nordestino e a possibilidade de utilização de subprodutos dessa atividade no manejo de afídeos, o objetivo do presente trabalho foi avaliar o efeito do extrato de própolis em diferentes concentrações sobre o comportamento e mortalidade do pulgão-verde ( $M$. persicae).

A própolis utilizada nos bioensaios foi obtida em colmeias de $A$. melifera localizadas no Campus Ciências Agrárias da Universidade Federal do Vale do São Francisco (CCA/UNIVASF) em Petrolina, PE. Após limpeza, as amostras foram trituradas, acondicionadas em frascos de vidro e estocadas em geladeira $\left(10^{\circ} \mathrm{C}\right)$. Para obtenção do extrato, adaptouse a metodologia de STRADIOTTI JÚNIOR et al. (2004). Foram utilizados $30 \mathrm{~g}$ de própolis triturada e macerada em $100 \mathrm{~mL}$ de solução alcoólica hidratada (70\%), por um período de 10 dias. Em seguida, a mistura foi submetida à filtragem, obtendo-se a solução estoque, a partir da qual foram feitas diluições para as concentrações de 10, 20, 30 e 40\% em água destilada.

O teor de fenóis totais dos extratos foi determinado pelo método espectrofotométrico de Folin-Ciocalteu (SLINKARD \& SINGLETON 1977) com modificações, empregando-se o ácido gálico como composto fenólico padrão e o conteúdo total de flavonoides foi determinado pelo método de VERMERRIS \& NICHOLSON (2006). Para determinação do teor de taninos condensados utilizou-se o método colorimétrico baseado na reação da vanilina com taninos em meio ácido.

Para avaliação do efeito dos extratos sobre o comportamento de $M$. persicae, foram realizados bioensaios de atratividade com e sem chance de escolha. No primeiro caso, extratos de própolis em diferentes concentrações foram testados individualmente em relação à testemunha. Considerando que o extrato foi preparado em solução alcoólica, utilizou-se como testemunha uma solução de água destilada + álcool, representando o tratamento com dose zero de própolis com o objetivo de quantificar apenas o efeito dessa substância sobre os insetos. Dessa forma, discos (Ø $3,0 \mathrm{~cm}$ ) de folhas de couve foram imersos nos extratos e na testemunha. Após evaporação do excesso de umidade, esses discos foram distribuídos de forma equidistante em uma placa de petri $(\varnothing 15 \mathrm{~cm})$ forrada com papel de filtro. Em cada placa foram distribuídos dois discos, opostos diametralmente, tratados com extrato e dois com água destilada + álcool na mesma proporção do tratamento avaliado (testemunha). No centro de cada placa foi realizada a liberação de 10 pulgões adultos. Foram utilizadas dez repetições para cada tratamento. A atratividade (número médio de pulgões atraídos para os discos foliares) foi avaliada aos 30, 60, 90 e 120 minutos após a liberação dos insetos.

O bioensaio de atratividade sem chance de escolha seguiu o mesmo procedimento que o anterior com a diferença de que, nesse caso, os discos $(\varnothing 4 \mathrm{~cm})$ tratados com extratos e água + álcool foram individualizados no interior de recipientes plásticos 
(Ø $14 \mathrm{~cm}$ ), de forma que os pulgões não tivessem opção de escolha entre os tratamentos. Nesse teste foram utilizadas quatro repetições por tratamento.

Para verificar o efeito dos extratos na mortalidade do pulgão-verde, em um recipiente plástico $(\varnothing 14 \mathrm{~cm})$ com o fundo coberto com espuma de poliuretano forrada com papel de filtro, foi colocada uma folha de couve com seu pecíolo envolvido por algodão hidrófilo umedecido com água destilada. Para cada tratamento foram utilizadas quatro repetições.

As folhas foram infestadas no dia anterior com fêmeas adultas do pulgão-verde para a obtenção de ninfas de mesma idade ( $1^{\circ}$ instar). No dia seguinte, as fêmeas adultas foram retiradas e foi realizada a contagem das ninfas produzidas. Os extratos de própolis em diferentes concentrações foram aplicados por aspersão sobre as folhas infestadas. Após evaporação do excesso de umidade, os recipientes foram tampados, identificados e mantidos em estufa incubadora tipo BOD com temperatura de $25^{\circ} \mathrm{C}$, umidade relativa $60 \% \pm 10 \%$ e fotoperíodo de 12 horas. Foi realizada avaliação após 24 horas da aplicação dos tratamentos, contabilizando-se o número de ninfas mortas. $\mathrm{O}$ experimento de mortalidade seguiu o Delineamento Inteiramente Casualizado, sendo os tratamentos constituídos pelos extratos $(10,20,30 \mathrm{e}$ $40 \%$ ) e uma testemunha (água + álcool) com quatro repetições.

Os dados foram submetidos à análise de variância e estudo da regressão para verificar o comportamento das variáveis em função do aumento na concentração dos extratos. No bioensaio de atratividade com chance de escolha, foi utilizado o teste LSD (Teste de Fisher) para comparar as médias, uma vez que as comparações foram feitas entre pares de médias (tratamento $\mathrm{x}$ testemunha).

A análise química da própolis utilizada revelou a presença de $3,2 \%$ de fenóis totais; $1,4 \%$ de flavonoides e $1,1 \%$ de taninos condensados. SILVA (2013) realizou a caracterização química de três própolis brasileiras coletadas nos estados do Ceará, Santa Catarina e Paraná. O teor de fenóis totais da própolis do Ceará $(2,41 \%)$ foi próximo ao encontrado no presente trabalho. Esse valor, entretanto, foi inferior aos encontrados no material proveniente do Paraná e Santa Catarina (11,78 e 11,70\%, respectivamente). Com relação aos flavonoides, os teores registrados para própolis coletadas no Ceará $(0,92 \%)$, Paraná $(1,52 \%)$ e Santa Catarina (3,32\%) foram próximos aos obtidos no material do CCA.
SILVA et al. (2006), ao analisarem amostras de própolis do Estado da Paraíba, colhidas em diferentes épocas de colheita, encontraram teores de fenóis variando entre 2,93 a $8,13 \%$, reafirmando que a composição química da própolis pode variar com o período de colheita.

LONGHINI et al. (2007) também determinaram flavonoides em própolis coletada no Paraná e encontraram uma concentração de $1,79 \%$ desses compostos no material avaliado.

Em estudo onde se analisaram própolis do Sudeste e Nordeste do Brasil e a influência da sazonalidade na composição química de fenóis e flavonoides, foi demonstrado por meio de espectrofotometria de absorção na região UV-visível, que a própolis oriunda do Nordeste, classificada como do tipo 6, apresenta um perfil de absorção distinto ao da região Sudeste, tipo 12 e uma composição química diferente, demonstrando variação da composição da própolis em diferentes regiões (CASTRO et al. 2007). As variações dos teores de fenóis totais e de flavonoides totais ocorrem em função de diferentes fatores, tais como a ecologia da flora local e região da coleta (PARK et al. 2002, BANKOVA 2005, SOUSA et al. 2007), período da coleta da resina (SANTOS et al. 2003) e genética da abelha rainha (PARK et al. 1998).

De acordo com MAYWORM et al. (2014), as própolis de origem brasileira apresentam conteúdos de taninos variando entre $1-4 \%$. As própolis que apresentam alto teor de tanino são as do tipo vermelha e verde, enquanto que nas marrons (própolis avaliadas neste estudo) encontram-se valores mais baixos, o que corrobora com os teores encontrados nas amostras analisadas. VOLZ \& CLAUSEN (2001) concluíram que compostos fenólicos, principalmente taninos, são reconhecidos por inibirem a herbivoria, pois em altas concentrações, tornam o substrato impalatável aos fitófagos.

Com relação à atratividade, não houve interação significativa entre os fatores (extrato de própolis $\mathrm{x}$ tempo de avaliação), ou seja, todos os tratamentos se comportaram de forma semelhante nos tempos avaliados. Quando os pulgões tiveram chance de escolha entre discos foliares tratados e não tratados, os tratamentos se comportaram de forma diferenciada somente nas concentrações de 10 e $40 \%$ (Figura 1A). $\mathrm{Na}$ menor concentração (10\%) verificou-se efeito atrativo do extrato, uma vez que foi registrado um número maior de insetos nos discos tratados quando 
comparado à testemunha. Na maior concentração (40\%), entretanto, o efeito foi inverso. Nesse caso, a testemunha atraiu mais insetos do que o disco tratado, comprovando a repelência do extrato, quando utilizado em concentrações maiores.

No teste de atratividade sem chance de escolha, os resultados obtidos também demonstraram atração do extrato de própolis na concentração de $10 \%$. A partir de $20 \%$, entretanto, verificou-se um processo inverso, ou seja, folhas tratadas com extrato apresentaram uma menor quantidade de pulgões conforme demonstra a equação de regressão obtida (Figura 1B).

O poder repelente da própolis foi relatado por BOONGIRD (2010), o qual afirmou que as abelhas usam a própolis como repelente para outros insetos que tentam invadir suas colônias. Esse fato já havia sido relatado por DUANGPHAKDEE et al. (2009), os quais verificaram ação repelente da própolis sobre formigas predadoras do gênero Oecophylla.

Com relação à mortalidade, na avaliação realizada após 24 horas da aplicação dos tratamentos sobre os pulgões, verificaram-se valores crescentes de

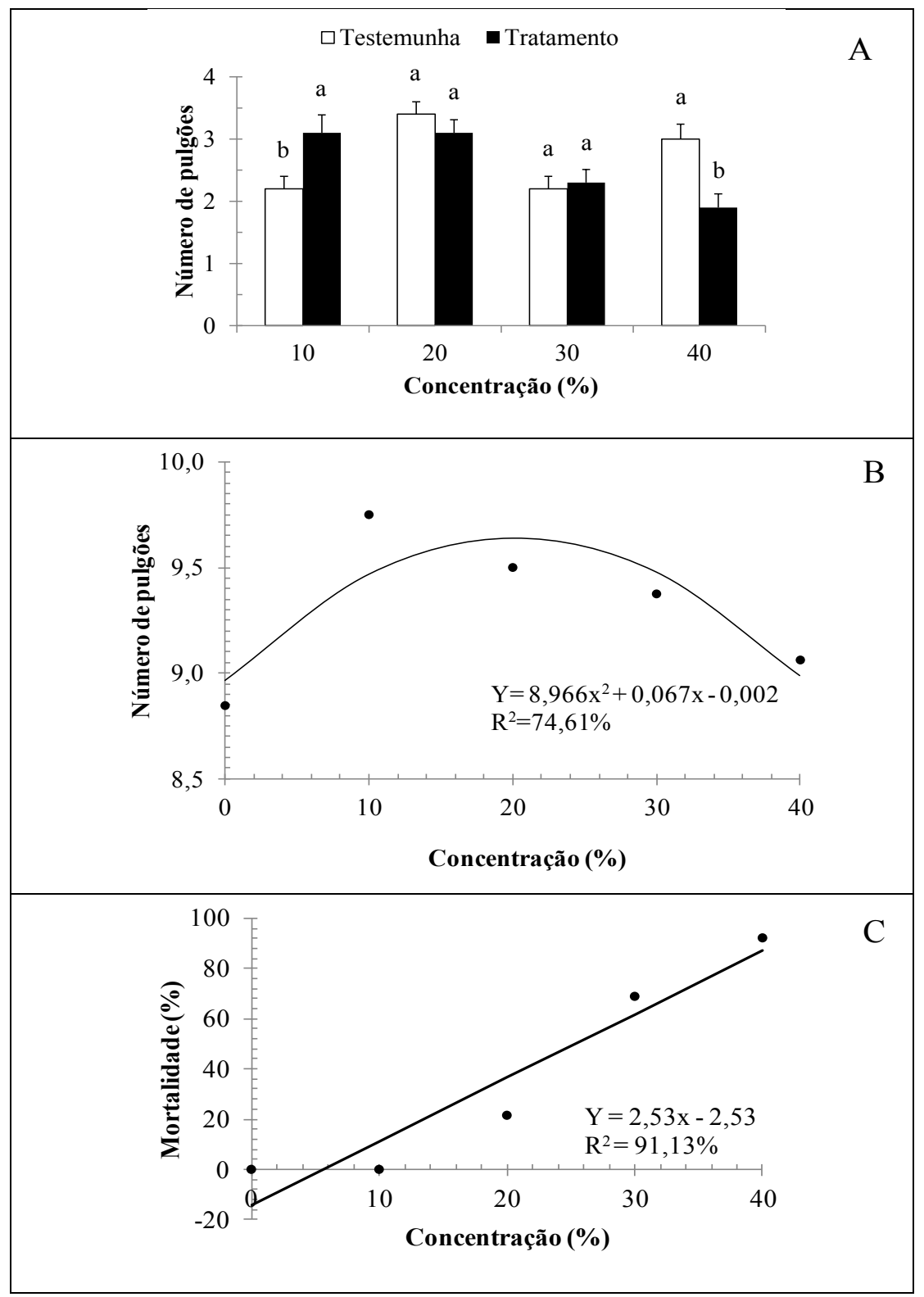

Figura 1. Efeito do extrato de própolis sobre M. persicae. A: Atratividade (teste com chance de escolha); B: Atratividade (teste sem chance de escolha); C: Mortalidade.

Figure 1. Effect of the propolis extract on M. persicae. A: Attractiveness (test free choice); B: Attractiveness (no-choice test); C: Mortality. 
mortalidade em função do aumento na concentração do extrato. $\mathrm{Na}$ menor concentração $(10 \%)$, à semelhança da testemunha não houve mortalidade de ninfas. Essa mortalidade atingiu 21,5; 68,9; e 92,2\% nas concentrações de 20, 30 e 40\%, respectivamente (Figura 1C).

SILVA et al. (2004) também verificaram ação de extratos de própolis sobre uma espécie de pulgão comum em cultivos de couve. Esses autores, entretanto encontraram níveis mais altos de mortalidade, uma vez que o tratamento do pulgão Brevicoryne brassicae (Linnaeus, 1758) com extrato na concentração de 5\% provocou $100 \%$ de mortalidade dos insetos uma hora após o tratamento.

OLIVEIRA et al. (2004) testaram a atividade inseticida do extrato de própolis em diferentes concentrações sobre larvas de Ascia monuste orseis (Latrielle, 1818) (Lepidoptera: Pieridae), em condições de laboratório. Após 24 horas da pulverização com extrato, os autores verificaram uma taxa de mortalidade de $87,5 \%$ na concentração de $25 \%$ do extrato.

FERREIRA et al. (2013), também observaram efeito negativo do extrato de própolis sobre parâmetros reprodutivos de fêmeas do carrapato Rhipicephalus (Boophilus) microplus (Canestrini, 1887). Os autores verificaram que o tratamento de ovos desse artrópode com extratos de própolis na concentração de $50 \%$ resultou em apenas $1,74 \%$ de eclosão dos mesmos. Esse valor foi significativamente menor do que o encontrado no tratamento controle que foi de $90,87 \%$.

Nas condições em que os experimentos foram conduzidos foi possível concluir que o extrato de própolis coletado em colmeias do CCA/Univasf afeta o comportamento e mortalidade do pulgãoverde. Esse extrato apresenta efeito tóxico sobre o pulgão $M$. persicae, provocando níveis crescentes de mortalidade à medida que se aumenta a concentração do mesmo. Além disso, em baixas concentrações, o extrato exerce atração sobre o inseto, sendo que em concentrações acima de $20 \%$, o mesmo se torna repelente a indivíduos da espécie. Esses efeitos, provavelmente estão relacionados aos teores de fenóis totais, flavonoides totais e taninos encontrados na própolis analisada, os quais apresentaram valores próximos aos padrões registrados na região Nordeste.

\section{REFERÊNCIAS}

BANKOVA V. 2005. Chemical diversity of propolis and the problem of standardization. The Journal of
Ethnopharmacology 100: 114-117.

BOONGIRD S. 2010. Honey and non-honey foods from bees in Thailand. In: DURST PB et al. Forest insects as food: humans bite back. Bangkok: Food and agriculture organization of the united nations regional office for Asia and the Pacific. p. 165-172.

CASTRO ML et al. 2007. Própolis do sudeste e nordeste do Brasil: influência da sazonalidade na atividade antibacteriana e composição fenólica. Química Nova 30: 1512-1516.

DUANGPHAKDEE O et al. 2009. Ant repellent resins of honeybees and stingless bees. Insectes Sociaux 56: 333339.

FERREIRA FBP et al. 2013. Avaliação in vitro do extrato alcoólico da própolis para o controle do Rhipicephalus (Boophilus) microplus. Arquivos de Ciências Veterinárias e Zoologia da Unipar 16: 107-112.

LONGHINI R et al. 2007. Obtenção de extratos de própolis sob diferentes condições e avaliação de sua atividade antifúngica. Revista Brasileira de Farmacognosia 17: 388395.

MACHADO LA et al. 2007. Uso de extratos vegetais no controle de pragas em horticultura. Biológico 69: 103-106. MAYWORM MAS et al. 2014. Does propolis contain tannins? Evidence-Based Complementary and Alternative. $4 \mathrm{p}$.

MILLER AL et al. 2010. Bioassays for monitoring insecticide resistance. Journal of Visualized Experiments 46: $1-5$.

OLIVEIRA HD et al. 2004. Efeito da aplicação de própolis na mortalidade de Curuquerê-da-couve (Ascia monuste orseis GODART Lepidóptera: Pieridae). In: XIV Congresso Brasileiro de Zootecnia, Brasília. CD-Rom.

PARK YK et al. 1998. Estudo da preparação dos extratos de própolis e suas aplicações. Ciência e Tecnologia de Alimentos 18: 313-318.

PARK YK et al. 2002. Própolis produzida no sul do Brasil, Argentina e Uruguai: Evidências fitoquímicas de sua origem vegetal. Ciência Rural 32: 997-1003.

PEREIRA AS et al. 2002. Própolis: 100 anos de pesquisa e suas perspectivas futuras. Química Nova 25: 321-326.

RAJABASKAR D et al. 2013. Dynamics of Myzus persicae arrestment by volatiles from Potato leafroll virus-infected potato plants during disease progression. Entomologia Experimentalis Et Applicata 148: 172-181.

SANTOS CR et al. 2003. Otimização do processo de extração de própolis através da verificação da atividade antimicrobiana. Revista Brasileira de Farmacognosia 13: 71-74.

SILVA CCF. 2013. Caracterização química de quatro amostras de própolis brasileiras. Isolamento de substâncias e testes das atividades antioxidante e anti-HIV. Tese (Doutorado em Botânica). São Paulo: USP. 130p.

SILVA RA et al. 2006. Características físico-químicas e atividade antimicrobiana de extratos de própolis da Paraíba, 
Brasil. Ciência Rural 36: 1842-1848.

SILVA RA et al. 2004. Efeito da aplicação do extrato de própolis na mortalidade do pulgão da couve (Brevironyne brassicae) (Homoptera: Aphididae). In: XIV Congresso Brasileiro de Zootecnia, Brasília. CD-Rom.

SLINKARD K \& SINGLETON VL. 1977. Total phenol analyses: automation and comparision with manual methods. The American Journal of Enology and Viticulture 28: 49-55.

SOUSA JPB et al. 2007. Perfis físico-químico e cromatográfico de amostras de própolis produzidas nas microrregiões de Franca (SP) e Passos (MG), Brasil. Revista Brasileira de Farmacognosia 17: 85-93.

STRADIOTTI JÚNIOR D et al. 2004. Ação do extrato de própolis sobre a fermentação in vitro de diferentes alimentos pela técnica de produção de gases. Revista Brasileira de Zootecnia 33: 1093-1099.

VAN DE VRIE M et al. 1972. Ecology of tetranychid mites and their natural enemies: A review. III. Biology, ecology, and pest status, and host-plant relations of tetranychids. Hilgardia 41: 387-403.

VERMERRIS W \& NICHOLSON R. 2006. Phenolic compound biochemistry. Netherlands: Springer. 276p.

VIÉGAS EKD. 2011. Propriedade antibacteriana da própolis verde sobre bactérias contaminantes da fermentação etanólica. Dissertação (Mestrado em Ciências). Piracicaba: ESALQ/USP. 70p.

VOLZ TJ \& CLAUSEN TP. 2001. Tannins in Puccinellia arctica: Possible deterrents to herbivory by Canada geese. Journal of Chemical Ecology 27: 725-732. 